\title{
Dimensions of Democracy within the Modern University
}

\author{
Vaia Papanikolaou ${ }^{1}$, loannis Roussakis ${ }^{2}$, Panagiotis Tzionas ${ }^{3}$ \\ 1,2 University of Thessaly \\ ${ }^{3}$ Alexander Technological Institute of Thessaloniki
}

\section{ABSTRACT}

A new association scheme for revealing dimensions of democracy within a modern university is presented in this paper. Certain indicators that have been internationally established and validated for the measurement of the institutional characteristics of Democracy and are monitored and stored in international databases, are examined and assessed for their applicability to the field of the University institutional characteristics, after appropriate adaptation. Various international organizations and research programs have as their main objective the systematic creation and support of specialized, time-spanning databases using variables and indicators and composing global reports that record and highlight the quality characteristics of democracy, both locally and globally. In the proposed research, in-depth analysis of the features presented in six of the most important and representative such databases and organizations, revealed a set of significant characteristics that are complementary to each other, providing a consensus for the construction of a common conceptual framework.

The University, on the other hand, is a multifaceted social institution with strong interactions with many and diverse sectors of society. Although its role and contribution to the general democratic societal operation has been studied to some extent, the way and specific processes of creation, establishment and interaction of the institutions that act internally at the university and its democratic operation, have not.

In this paper the 'democratic' university is approached through its mission, the multifunctional operations it performs and its complicated and highly complex interactions with all societal actors, the industry, the labor market and the respective government bodies. Essentially, it is an attempt to systematically approach and analyze democratic institutions embedded within the university, or even to identify their possible inherent or acquired weaknesses, through the selection and adaptation of valid sets of indicators used for democracy, as these are portrayed on the conceptual framework proposed in this research.

Keywords: Democratic indicators, university characteristics, educational policy. 